\title{
TERCEIRIZAÇÃO NO BRASIL: o embate entre sindicatos e patronato
}

\author{
Marcia de Paula Leite*
}

\begin{abstract}
Este artigo visa a discutir a reação dos sindicatos brasileiros ao processo de terceirização do trabalho, desde quando o processo tomou maior vulto a partir da última década do século passado, até sua extensão a todas as atividades econômicas, em 2017. O texto leva em consideração especialmente a ação das centrais sindicais frente às práticas empresariais, ao mesmo tempo que discute as mudanças na legislação promovidas desde os anos 1990. Ao recuperar a atuação sindical, a análise centra-se no vigoroso embate travado entre os sindicatos e o empresariado no período 2003-2016, em que os sindicatos protagonizaram uma luta ferrenha contra o projeto empresarial de expandir a terceirização a todas as atividades econômicas, e conclui no sentido de que a capacidade de intervenção do movimento sindical consistiu num dos fatores que levaram as classes dominantes a promover o impeachment de 2016. O texto se baseia na discussão da bibliografia e em resultados de pesquisas que venho desenvolvendo nas últimas décadas.

Palavras-chave: Terceirização interna. Terceirização externa. Terceirização irrestrita. Centrais sindicais. Protagonismo sindical.
\end{abstract}

\section{INTRODUÇÃO}

Desde as décadas finais do século passado, o trabalho tem estado em meio a um quadro de profundas transformações, geradas por diferentes fatores que têm atuado simultaneamente sobre suas características, suas formas de organização e os direitos a ele associados. Tais fatores estão relacionados não só à entrada em cena de um novo regime de acumulação - o neoliberalismo - que, juntamente com os processos de globalização e financeirização da atividade econômica, tem promovido uma contínua deterioração do trabalho, mas também ao desenvolvimento tecnológico que, com a chegada da inteligência artificial, tem permitido o surgimento de formas ainda mais precarizadas de trabalho, como as relacionados à economia de plataforma, ou para utilizar o termo em inglês, a gig economia. No centro dessas modificações encontra-se o processo de terceirização do trabalho, provocado, seja pela

* Universidade Estadual de Campinas (Unicamp). Faculdade de Educação.

Rodovia Professor Zeferino Vaz, Rua Bertrand Russell, 801. Cidade Universitária Cep: 13083-865. Campinas São Paulo - Brasil.mpleite48@gmail.com https://orcid.org/0000-0001-9366-7071 externalização dos processos promovida pelas empresas (a expansão da empresa enxuta), seja pela internalização de mão de obra subcontratada, ambas adotadas como forma de tornar as empresas mais flexíveis às variações do mercado e diminuir os custos do trabalho.

Este artigo visa a discutir a reação dos sindicatos brasileiros à terceirização do trabalho, desde quando o processo tomou maior vulto a partir da última década do século passado, até sua extensão a todas as atividades econômicas, em 2017. O texto leva em consideração especialmente a ação das centrais sindicais frente às práticas empresariais, ao tempo em que discute as mudanças na legislação promovidas desde os anos 1990. Ao ir recuperando a atuação sindical, evidenciando inclusive a criação de uma nova institucionalidade, como o Fórum Nacional Permanente em Defesa dos Direitos dos Trabalhadores Ameaçados pela Terceirização, o texto evidencia o cada vez mais forte protagonismo sindical, no qual baseia seu argumento principal, qual seja, o de que a capacidade de intervenção do movimento sindical consistiu num dos fatores que levaram as classes dominantes a promover o impeachment de 2016. 
Ao centrar-se nessa hipótese, seu escopo vai apenas até 2017, quando os sindicatos são derrotados em sua luta contra a terceirização irrestrita. Destaque-se que discutir o papel do movimento sindical na luta contra a terceirização adquire relevância, tanto se consideramos a importância do fenômeno para a qualidade do trabalho e do emprego, quanto o fato de que esse papel é ainda uma questão em discussão.

Para cumprir com esses objetivos, o texto se desenvolverá em três partes, além desta introdução: a primeira, destinada a discutir o próprio conceito de terceirização, o contexto internacional em que o fenômeno se difunde e as formas de que ele se reveste; outra dedicada à análise da evolução da terceirização na prática das empresas e na mudança da legislação, concomitantemente à ação sindical frente às transformações; e a terceira, voltada às considerações finais. O texto se baseia na discussão da bibliografia e em resultados de pesquisas que venho desenvolvendo nas últimas décadas.

\section{TERCEIRIZAÇÃO: definição, con- texto e expansão}

Embora esteja no âmago da atual organização empresarial, a terceirização é um fenômeno complexo e difícil de ser conceitualizado. A definição mais comum é aquela que se refere à interposição de uma empresa terceira $\widetilde{\delta}$ entre o trabalhador e a empresa tomadora do กิ meio da qual ele não tem acesso aos direitos trabalhistas e previdenciários. Nesse sentido, tomarei aqui a definição de Faria (2014, apud Véras de Oliveira, 2015), na qual a terceirização é entendida como toda forma de trabalho em que ocorre "transferência de atividades e responsabilidades para terceiros", adicionando a contribuição de Biavaschi e Droppa (2015, p. 127) de que ela deve ser compreendida de maneira "ampla, tanto externa, como interna às empresas", incluindo, portanto, todas as formas de trabalho autônomo que em vez de exercido por conta própria, é realizado por conta alheia, ou seja, de forma subordinada.

Não se configurando como um fenômeno novo, a terceirização já existiu em momentos prévios do capitalismo, como no putting out system, sob o qual se organizava a produção nos idos da revolução industrial. Essa forma de subcontratação diminuiu, porém, com a evolução do capitalismo, voltando a ser utilizada de forma intensa apenas em sua fase contemporânea. Nesse sentido, a terceirização, tal como se configura atualmente, é um fenômeno característico do regime vigente de acumulação, que começou a se desenhar nos anos 1970, quando se desfez o acordo que deu lugar às sociedades do bem-estar social nos países centrais. Na nova conjuntura internacional, o capital buscou sair da crise de meados da década por meio da recuperação de suas margens de lucro, cenário em que os ideais do neoliberalismo se impuseram, com suas propostas de cortes de gastos e custos. Para tanto, foram buscadas outras formas de organização das empresas e do trabalho, bem como novos modos de relacionamento das empresas com trabalhadores e sindicatos.

Os processos de terceirização vão modificar esse quadro no qual ocorre a configuração das empresas, que começam a externalizar partes do processo produtivo (terceirização externa) e a promover formas de contratação do trabalho por meio de empresas terceiras (terceirização interna) de modo a baratear os custos do trabalho. Vale lembrar que ao mesclar 
trabalhadores contratados diretamente com aqueles contratados por empresas terceiras, com acessos diferenciados a benefícios, remunerações e jornadas de trabalho, muitas vezes trabalhando lado a lado, essa última forma de terceirização acaba por criar uma categoria discriminada de trabalhadores com menos direitos, uma subespécie de trabalhadores que, nas palavras de Viana (2012), é praticamente alugada pela empresa terceira à tomadora.

Registre-se ainda a dupla subordinação dos trabalhadores terceirizados, devido a que as empresas tomadoras de serviços realizados por terceirizadas nem sempre se retiram do comando da atividade terceirizada, gerando "um duplo exercício do poder empregatício, por contratante e contratada” (Dutra, 2016, p. 75). Os estudos que ressaltam a relação entre a terceirização interna e formas degradadas de trabalho são inúmeros, valendo destacar a relação encontrada entre o trabalho terceirizado e acidentes e mortes no trabalho e a ocorrência de formas de trabalho análogas à escravidão (Druck e Filgueiras, 2014; Coutinho, 2016, Filgueiras, 2016; Dieese, 2014), Convém salientar, porém, que a terceirização interna é mais fácil de ser regulada por medidas normativas do que a externa, que depende do modo de organização das empresas, sobre o qual a legislação possui menor poder de interferência. Desse modo, enquanto as formas de controle da terceirização externa ficam mais na dependência da capacidade de negociação dos trabalhadores e sindicatos com o patronato, a terceirização interna pode ser controlada pela legislação, que pode permiti-la ou não, restringi-la a determinadas atividades ou situações, e estabelecer se ela é subsidiária ou solidária ${ }^{1}$. Nessas condições, a regulação da terceirização interna por meio da legislação se coloca no centro das disputas entre capital e trabalho.

Vale lembrar ainda que o processo de terceirização externa se aprofundou de tal manei-

${ }^{1}$ A responsabilidade solidária não pode ser presumida devido a que suas hipóteses são previstas em lei ou pactuadas entre as partes. Já a subsidiária possui caráter acessório ou suplementar; há uma ordem a ser observada para a cobrança da dívida, na qual o devedor só pode ser acionado após a dívida não ter sido totalmente executada. ra que acabou por mudar totalmente a configuração das empresas em escala internacional. Por um lado, algumas atividades, anteriormente desenvolvidas internamente às empresas, acabaram por gerar, no processo de externalização, o surgimento de novos setores de atividade, como o de tele atendimento. Por outro lado, com a globalização, a terceirização externa deu lugar a cadeias globais de valor, em que grandes empresas externalizam a manufatura de seus produtos para outros países, mantendo internamente as parcelas mais lucrativas do processo produtivo. Isso acontece, por exemplo, no setor eletroeletrônico, no qual a concepção dos produtos está concentrada nas marcas, que atuam nos países centrais, a produção dos componentes se aglutina em empresas asiáticas e a montagem em países da periferia. ${ }^{2}$

Essa forma de terceirização é também precarizadora do trabalho por separar fisicamente a produção de parcelas mais simples do processo produtivo, fragilizando o poder de negociação de seus/suas trabalhadores/as, ao mesmo tempo em que confina grupos discriminados de trabalhadores/as, como mulheres e negros, nos últimos elos dos encadeamentos, onde o trabalho é mais precário. Ela se tornou, porém, constitutiva da organização das empresas no quadro atual do capitalismo (Carneiro,2007; Leite,2003). O pior é que o aprofundamento da terceirização provoca demissões em massa nas grandes empresas, promovendo o enxugamento dos trabalhadores no polo onde o trabalho se qualifica, em função do abandono das formas tayloristas de organização do trabalho e do enriquecimento de tarefas ${ }^{3}$ e o aumento do trabalho precário nos demais elos das cadeias.

Foram muitas as pesquisas que apontaram esse processo de degradação do trabalho conforme se percorriam as cadeias que se

${ }^{2}$ Isso faz com que os efeitos da terceirização externa sejam distintos para os trabalhadores dos países centrais e os dos periféricos, embora isso não signifique que o processo não gere degradação do trabalho lá também.

${ }^{3}$ Há uma ampla bibliografia que trata das novas formas de organização do trabalho que vieram substituir o fordismo, notadamente nas empresas industriais. Ver, entre outros, Piore e Sabel, 1984; Coriat, 1993; Castro, 1995. 
estavam formando, tanto no setor industrial, como no de serviços, indicando a pressão que as empresas líderes faziam sobre seus fornecedores para diminuir o custo de seus produtos e serviços, o que acabava redundando em cortes de salários e benefícios ao longo das cadeias (Conceição, 2008; Leite, 2003; Segnini, 1999).

Os efeitos da terceirização sobre o trabalho foram registrados também por estudos sobre o mercado de trabalho, que assinalaram incremento do trabalho mal remunerado, sem direitos e degradado no final da década. No mesmo sentido apontaram as pesquisas que se debruçaram sobre trajetórias de trabalhadores demitidos das empresas líderes dos setores automobilístico e químico (Cardoso, 1998; Castro et al., 1997), as quais revelaram que parte importante deles era expulsa do setor e/ou não lograva mais acessar empregos formais.

Outra questão na análise da terceirização consiste em suas implicações sobre a organização sindical. Ao fragmentar o coletivo de trabalhadores em empresas distintas; em contratados diretos e indiretos, com diferentes acessos a benefícios, salários e direitos; e em distintas categorias, os efeitos da terceirização sobre os sindicatos são desastrosos. Lima esclarece esse processo de enfraquecimento dos sindicatos ao sublinhar que:

entre as consequências para os trabalhadores do trinômio flexibilização-terceirização-precarização, podemos reiterar de forma mais detalhada a questão da perda de uma identidade formada no coletivo de trabalho. Não que este coletivo também desapareça, mas... é um coletivo fragmentado, com distintas formas de contrato e inserção que dificulta uma percepção conjunta de pertencimento (Lima, 2010, p.24).

Indo mais além, Delgado (2009, apud Coelho, 2016, p. 129) acredita que a terceirização desordena a atuação sindical e na prática "suprime qualquer possibilidade e\caz de ação, atuação e representação coletivas dos trabalhadores terceirizados".

\section{Terceirização na Prática, na Lei e na Ação Sindical}

A evolução da terceirização na prática das empresas e na mudança da legislação se intensificou de maneira constante entre o início dos anos 1990 e 2017. Já a ação sindical se modificou, podendo ser dividida em dois períodos: um primeiro, correspondente aos anos 90, em que, aturdidos pelo conjunto de mudanças e frente a uma difícil conjuntura, os sindicatos revelaram fraca capacidade de reação e, um segundo, ao longo do período que vai de 2003 a 2017, em que eles empreenderam uma incansável batalha contra a terceirização, que foi num crescendo, tornando cada vez mais difícil a implementação do projeto empresarial. Essa capacidade de intervenção do movimento sindical, numa conjuntura política que se tornou mais favorável à sua ação, consistiu, a meu juízo, num dos fatores que levaram as classes dominantes a promover o impeachment de 2016.

\section{Os Difíceis Anos 1990}

As pesquisas do início dos anos 90 revelavam que as políticas de reestruturação das empresas centravam-se na terceirização externa, com a contínua transferência de atividades empresariais para fornecedores. Isso tinha a ver com o fato de que até 1993 não havia regulamentação específica para a terceirização, dando lugar a que ela fosse regida pelo contrato de trabalho temporário, que o permitia no setor privado, por meio de contratação mediante empresas prestadoras de serviços que disponibilizavam mão de obra temporária. Como notam Biavaschi e Santos, é nesse vácuo normativo que "o TST normatizou e, via Resolução $n^{\circ}$ 04/86, de 22 de setembro de 1986, introduziu em seus enunciados o Enunciado $\mathrm{n}^{\mathrm{0}} 256$ ”, com um texto que, na verdade, coibia a terceirização: 
Salvo os casos de trabalho temporário e de serviço de vigilância, previstos nas Leis ns. 6.019, de 03.01.74, e 7.102, de 20.06.83, é ilegal a contratação de trabalhadores por empresa interposta, formando-se o vínculo empregatício diretamente com o tomador de serviços. (Biavaschi; Santos, 2014, p. 26).

A regulamentação da terceirização passou a ser regida a partir de 1993 pelo Enunciado 331 do TST que também considerava ilegal a contratação de mão de obra por empresa interposta. Mas, ao estender a exceção aos serviços de conservação e limpeza e aos serviços especializados vinculados à atividade meio da empresa tomadora, o Enunciado abriu a possibilidade de disseminação da terceirização. $\mathrm{O}$ país assiste, assim, a uma intensa difusão da terceirização externa e interna, como detectado por vários estudos (Martins e Ramalho, 1994; Franco e Druck, 1997; Borges e Franco, 1997; Druck, 1999; Krein, 2007).

Pegos de surpresa pelas mudanças na organização das empresas, nas formas de contratação, na organização do trabalho, nos modos de gestão, além da introdução de novos equipamentos microeletrônicos, os sindicatos demonstraram pouca capacidade de reação nesse momento. As exceções consistiram em acordos feitos por comissões de fábrica, sobretudo no setor automotivo do ABC paulista, onde ocorreram negociações, "basicamente de modo bilateral (sindicato/empresa)" (Bresciani, 1997, p. 92).

Ao mesmo tempo, a CUT se manifestava contra a terceirização da mão de obra nas resoluções do $5^{\circ}$ Congresso Nacional, em 1994, denunciando seu caráter de super exploração. Segundo Costa (2016, p. 214), a terceirização significava para a Central "salários rebaixados, precárias condições de trabalho, divisão e desorganização dos trabalhadores e trabalhadoras, calote no recolhimento de encargos e no pagamento de verbas rescisórias dos trabalhadores", motivo pelo qual incluiu o combate à terceirização em sua Plataforma de Lutas " e estabeleceu as primeiras premissas do que viria a constituir sua proposta de regulamenta- ção: igualdade de salário e direitos, representação pela categoria preponderante”.

Essas conquistas e movimentações não foram suficientes, porém, para diminuir o avanço do fenômeno. O intenso movimento de terceirização, bem como a orientação governamental favorável ao mesmo, levou o governo a lançar o PL 4.308/1998. Na mensagem do PL, o então presidente da República, Fernando Henrique Cardoso, o justificava pela inserção da economia brasileira no mercado internacional e a necessidade de modernização das formas de produção, ressaltando a urgência de adaptação dos instrumentos normativos trabalhistas em busca de maior flexibilização nas formas de contratação.

Embora o projeto não tenha sido votado, a Lei 9.601, também de 1998, sobre o contrato de trabalho com prazo determinado buscou essa adaptação, considerando a empresa terceira como uma pessoa jurídica de direito privado que presta serviços determinados e específicos a terceiros, viabilizando a pejotização. ${ }^{4}$ Ademais, a possibilidade de que a contratante também pudesse terceirizar, permitiu a terceirização em cascata, promovendo a fragmentação dos processos produtivos. Ao mesmo tempo, o empresariado passou a pressionar pela reforma da legislação, buscando estender a terceirização a todas as atividades econômicas. Em 2000, embora não tenha logrado o pretendido, ele conseguiu uma modificação na Súmula 331, estendendo a responsabilidade subsidiária pelos trabalhadores terceirizados para o setor público (Biavaschi e Droppa, 2015).

As dificuldades para os sindicatos se defenderem da terceirização apareciam tanto no que tange à degradação do trabalho daqueles que eram terceirizados, trazendo novos temas à tona, como no que concerne à fragmentação dos trabalhadores e à perda de seus efetivos. Os estudos refletiam essa realidade em vários

${ }^{4}$ A "pejotização", refere-se à prestação de serviço por empresa de uma só pessoa (Pessoa Jurídica), um mecanismo que, como já sublinhado, burla a legislação trabalhista ao transformar um contrato de trabalho em um contrato de prestação de serviços entre a pessoa jurídica do empregado e a empresa contratante. 
setores e regiões do país (Druck, 1999; Ramalho, 2008; Dau, 2009; Conceição e Lima, 2009; Marcelino, 2013; Véras de Oliveira, 2015).

Analisando pormenorizadamente o sindicalismo da CUT, Véras de Oliveira (2015, p. 551) observa que quanto mais se ampliava a distância entre os trabalhadores mais estáveis (cada vez em menor número) e os precarizados (em crescimento), "mais difícil era para o Sindicalismo CUT realizar o seu projeto de representação do conjunto da classe trabalhadora”, sobretudo quando se considera o contexto dos anos 90, em que os sindicatos sofriam derrotas tanto no campo da negociação coletiva, pela diminuição de seu poder de barganha efetiva, como no campo da ação política, no qual perdia o protagonismo político de que gozara nos anos 80 e via reduzida sua capacidade de pautar a agenda política do país.

De fato, depois do processo de fortalecimento e organização promovido durante os anos 80, o movimento sindical se viu imerso em uma mudança da conjuntura, em que a entrada do país na globalização e a adoção de políticas neoliberais corresponderam a um ataque ao trabalho e aos sindicatos. Ademais, em termos econômicos, o país viveu quase todo o período em situação de crise: embora a gravidade da crise aberta em 1990 tenha arrefecido em 92 - e a situação tenha se tornado mais favorável à economia após a estabilização inflacionária com o Plano Real em 94 - nova crise సิ se abriu em 97 e a economia continuou patiจิ ¿. a informalidade recrudesceu, os salários baiङु xaram e o tempo médio de desemprego passou

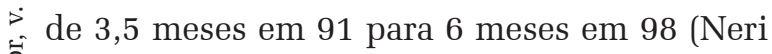
et al, 2.000). Além disso, a privatização de empresas estatais provocou demissões em massa de setores organizados da classe trabalhadora, ao mesmo tempo que direitos trabalhistas eram retirados. Esses fatores não podiam deixar de repercutir sobre a capacidade sindical de enfrentar as transformações, notadamente quando se considera que eles geravam mudanças estruturais que afetavam a capacidade dos sindicatos para organizar, mobilizar e defender os trabalhadores.

\section{O Protagonismo Sindical nos Anos 2003- 2016}

A conjuntura mudou, porém, a partir de 2003, com a ascensão do PT à Presidência e com a abertura de um contexto internacional de valorização das commodities, que favorecia a economia brasileira. Com isso, o pêndulo mudou de direção, agora mais favorável aos sindicatos e a mudança da lei tal como pretendida pelo patronato se tornava mais difícil. Por um lado, o governo já não se mostrava favorável a uma modificação normativa que liberasse totalmente a terceirização, substituindo a pressão exercida pelos governos anteriores nesse sentido pela busca de uma negociação que atendesse aos interesses empresariais sem descarregar o peso da terceirização sobre os trabalhadores. Por outro lado, o fato de o movimento sindical ter abraçado a luta contra a terceirização de maneira mais firme, enfraquecia as pretensões patronais. É nesse quadro que os sindicatos assumem nova estratégia, apresentando uma postura mais ofensiva, e empreendem uma batalha contra a terceirização, para a qual o acúmulo adquirido na fase anterior pode ter sido importante. Por meio de um intenso embate com o empresariado, em que evidencia capacidade propositiva, o movimento sindical promove uma árdua resistência à institucionalização da regulação pretendida pelo empresariado, a qual só diminuirá com o golpe de 2016.

Já no $8^{\circ}$. Congresso, em 2003, a CUT aprova "o combate à terceirização no setor público, com exigência de concursos públicos" e se propõe a "lutar pelo fortalecimento da fiscalização do trabalho contra a terceirização fraudulenta e propor limites" para restringir a terceirização (Costa, 2016, p. 214). Em 2004, 
enquanto o empresariado apresentava o PL 4330/04, que estendia a terceirização a todas as atividades econômicas, a Central cria um Grupo de Trabalho (GT de Terceirização), que tinha como objetivo

compor um grupo de trabalho interno, no qual as confederações nacionais orgânicas à central teriam a tarefa de debater as consequências da terceirização em suas bases, levantando informações e dados, na busca da compreensão do fenômeno. Esse processo interno teve um papel formativo fundamental, que preparou a CUT para os embates futuros (Costa, 2016, p. 215).

Destaque-se ainda que nele foi gestada a proposta de Projeto de Lei que o deputado federal Vicentinho apresentou na Câmara em 2007. Embora o projeto não tenha prosperado, ele demonstrou o ímpeto da Central em disputar a regulamentação da terceirização. Dau (2009, p. 182) registra alguns saldos que poderiam ser contabilizados nesse momento: o fato de que, passando por cima dos entraves da estrutura sindical oficial, alguns sindicatos filiados à Central já representassem politicamente trabalhadores terceirizados, celebrando acordos coletivos; a consolidação de iniciativas sindicais tomadas na busca de igualdade de condições e remuneração do trabalho; a ocorrência de alterações nos estatutos dos sindicatos para incluir a representação de trabalhadores terceirizados; a unificação das ações nos locais de trabalho por meio do aproveitamento de espaços de representação já constituídos.

A própria CUT considerou, porém, na Plenária Nacional de 2008 que, em termos concretos os resultados foram parcos (Veras de Oliveira, 2015) e aumentou a pressão, trazendo as demais centrais para a luta: em 2009, o projeto de lei da CUT serviu de base para a elaboração de um novo projeto (Projeto das Centrais) para se contrapor ao PL 4330/04. Embora não tenha chegado a tramitar no Congresso, o Projeto das Centrais se contrapôs ao PL 4330/04 em todo processo de negociações. (Costa, 2016).
A ofensiva sindical não foi suficiente, porém, para que o empresariado se detivesse em seu movimento de terceirizar e pressionar pela extensão da terceirização ao conjunto das atividades. O aumento da terceirização, durante os anos 2000 foi reportado por inúmeros estudos que indicavam sua disseminação. Em conferência proferida em 2011, Pochmann considerava que o processo fora tão intenso nas décadas anteriores que se podia equiparar "a terceirização de mão de obra a uma quase reforma trabalhista, por possibilitar uma alteração significativa na forma de funcionamento do mercado de trabalho brasileiro" (Pochmann, 2007, sp)

Referindo-se ao mesmo fenômeno, Druck e Filgueiras registram uma verdadeira "epidemia da terceirização”, com efeitos calamitosos sobre o trabalho:

\begin{abstract}
A relação entre terceirização e precarização do trabalho é direta e demonstrada fartamente pelas pesquisas em todo país, envolvendo diversas abrangências, setores, funções e aspectos da relação de emprego, caracterizando uma verdadeira epidemia. Essa relação é ainda mais radical do que normalmente apresentada, pois atinge os dois aspectos essenciais do assalariamento, quais sejam a dignidade e a própria vida dos trabalhadores (Druck; Filgueiras, 2014, p.107).
\end{abstract}

Nesse quadro de expansão da terceirização o empresariado intensificou seu questionamento ao Enunciado 331, considerando-o restritivo e uma ingerência do Estado sobre suas atividades. Exacerbou também as queixas de que a lei não estipulava quais seriam as atividades meio e fim, dificultando sua aplicabilidade e, aproveitando-se dessa dubiedade, multiplicou a terceirização de atividades fim ao arrepio da lei, tornando-a inócua em vários setores. Essa prática se espalhava por todo o país e, segundo o Dieese, as condenações por terceirização ilícita, repetiam-se aos milhares pelo Brasil (Dieese, 2014, p. 26).

Nesse processo, despontam setores que baseiam sua estratégia de competitividade na terceirização, como a indústria eletroeletrônica 
(Lapa e Leite, 2017) e da confecção (Freire da Silva, 2008), ao lado de outros que, ajudados pelo avanço tecnológico e o surgimento da inteligência artificial, se apoiam inteiramente no trabalho terceirizado, como o dos trabalhadores por plataforma (Almeida; Kalil e Fonseca, 2021).

As lutas continuaram na década seguinte e em 2011 veio à tona mais um resultado dos trabalhos do GT de Terceirização, o Dossiê da Terceirização, numa parceria entre a CUT e o Dieese. Dimensionando a terceirização e suas implicações sobre os/as trabalhadores/as e discutindo as propostas do movimento sindical, o dossiê se tornou uma referência e um instrumento de luta para os sindicatos.

Nesse mesmo ano, durante a tramitação do PL 4330/04 na Câmara, foi instalada uma Comissão Especial para promover estudos e proposições de regulamentação da terceirização, na qual ocorreu a quebra na unidade das centrais. Como nota Costa (2016, p. 217), o então relator, vice-presidente da UGT, sob influência do presidente da Força Sindical, apresentou um substitutivo ao projeto, o qual conservava o caráter precarizador da proposta. Esse apoio da UGT e FS ao projeto 4330/04 foi criticado pelas demais centrais, que consideraram que o substitutivo reforçava a terceirização em vez de combatê-la, já que, "em vez de estabelecer a distinção entre atividade-meio e atividade-fim, introduzia a possibilidade de contratação de serviços especializados de qualquer natureza" సิ (Marcelino e Galvão, 2020, p. 164).

Nesse processo de ampliação e complexificação da luta, o TST convocou uma Audiência Pública, em outubro de 2011, da qual participaram representantes de empresas e trabalhadores, juristas, pesquisadores e estudiosos, que apresentaram suas interpretações sobre a terceirização e, no mês seguinte, foi criado o Fórum em defesa dos trabalhadores ameaçados pela terceirização, com a participação de entidades de trabalhadores e pesquisadores, de Centrais Sindicais, lideranças sindicais e de trabalhadores, professores e pesquisadores (Biavaschi e Santos, 2014). O Fó- rum constituiu-se num espaço de discussão a respeito das implicações da terceirização sobre os/as trabalhadores/as, as possíveis maneiras de controlá-las e encampou os princípios do PL das centrais. Em meio a essa agitação, o movimento sindical logrou uma vitória importante: a suspensão da tramitação do PL n ${ }^{\circ} 4330 / 04$ e a abertura de debates com o Governo Federal sobre o tema, em junho de 2013. A partir desses debates, foi criada uma mesa quadripartite para discutir o tema, formada pelo Governo Federal, o Congresso Nacional, as Centrais Sindicais dos Trabalhadores e o patronato, tendo em vista a elaboração de um projeto de consenso. Segundo Biavaschi e Santos (2014), as pressões de alguns partidos políticos, de magistrados, trabalhadores, acadêmicos, artistas e do Fórum, assim como uma nota pública de Ministros do TST contrários ao PL no 4330 concorreram para que o projeto saísse de pauta.

Todavia, a mesa quadripartite fracassou, provocando o recrudescimento da pressão dos empregadores e dos trabalhadores sobre o governo federal. Em meio a essa disputa, o Fórum aprovou em setembro de 2013 uma nota pública em defesa dos trabalhadores. A seguir, buscando atualizar os dados do primeiro dossiê sobre a terceirização, a CUT e o Dieese lançaram em novembro de 2014, outra versão do Dossiê da Terceirização, com dados alarmantes sobre as consequências do processo: os trabalhadores terceirizados já correspondiam a 26,8\% do mercado formal de trabalho, totalizando 12,7 milhões de assalariados (Dieese, 2014, p.13); a remuneração era $24,7 \%$ menor para os trabalhadores terceirizados; a jornada de 3 horas a mais semanalmente, sem considerar horas extras ou banco de horas (Dieese, 2014, p. 14); a rotatividade dos terceirizados era de $64,4 \%$ contra 33\% dos diretamente contratados (Dieese, 2014, p. 15); o não cumprimento das obrigações trabalhistas, principalmente ao final dos contratos de prestação de serviços, era uma realidade no mundo da terceirização (Dieese, 2014, p. 21); a alta incidência de mortes e acidentes de trabalho (Dieese, 2014, p. 23) indica- 
vam "que o lado mais perverso da terceirização são os acidentes e as mortes no trabalho, que acontecem em diversos setores da atividade econômica”, evidenciando que, "devido à precarização causada pela terceirização, o trabalhador paga um preço alto, muitas vezes com a própria vida" (Dieese, 2014, p. 26).

O impacto do dossiê gerou reação dos empresários, que lançaram um estudo crítico ao material, com outros dados e interpretações sobre a terceirização (Costa, 2016), ao mesmo tempo que produziram vídeos e artigos ressaltando os aspectos positivos do PL n ${ }^{\circ} 4330 / 04$. Ademais, o setor defendeu a Repercussão Geral proposta pelo Supremo que considerava que, a restrição da terceirização às atividades-meio por via da Súmula 331, o TST feria o princípio da "livre iniciativa" (Biavaschi e Santos, 2014).

Como relatam Marcelino e Galvão, o projeto 4330/04 foi recolocado em votação em 2015, em regime de urgência pelo então líder do PMDB, Eduardo Cunha, promovendo forte reação sindical: foram realizadas três jornadas de luta contra o projeto, com massivas manifestações de rua e paralisações de categorias importantes. De acordo com as autoras,

as manifestações foram convocadas por quase todas as centrais sindicais atuantes, inclusive Conlutas e Intersindical - centrais que surgiram de rupturas com a cut e com a qual apresentavam várias diferenças. A Força Sindical foi a única ausente dos protestos. Retomando, em parte, os argumentos favoráveis à flexibilização de direitos que marcara seu posicionamento nos anos 1990 (Trópia, 2009), essa central ficou isolada na defesa do projeto. Mas, diante da expressiva reação das ruas e da oposição das instituições de regulação do trabalho (Anamatra, Ministério Público do Trabalho), até mesmo a Força Sindical começou a subscrever críticas a ele (Marcelino e Galvão, 2020, p. 164).

Porém, o quadro favorável ao sindicalismo já começara a se transformar novamente a partir de 2012, quando a situação econômica do país se alterou e medidas mais duras do governo em relação ao trabalho começaram a ser tomadas. Ademais, nesse contexto de luta do movimento sindical ao projeto de terceirização, bem como às propostas patronais de reformas trabalhista e da previdência, que se apresentavam com cada vez maior insistência -associado à crise econômica e política aberta no segundo governo Dilma - a conspiração contra seu governo se intensificara, culminando com o golpe de 2016. Nesse momento, a intensidade do ataque empresarial aos direitos trabalhistas se evidenciava na quantidade de projetos que se encontravam no Congresso Nacional (mais de 55) que, de acordo com a Federação dos TrabaIhadores do Ramo Químico da CUT no Estado de São Paulo, "de alguma forma reduzem ou flexibilizam direitos" (FETQUIM. 2016, p. 13).

Com a mudança de conjuntura promovida pelo golpe, o governo Temer apressou-se em propor as reformas trabalhista e da previdência, bem como a extensão da terceirização a todas as atividades econômicas. É nesse contexto que foi aprovado, o PL 4.302/1998, de autoria do governo Fernando Henrique. O projeto, que tinha como alvo principal a regulamentação do trabalho temporário, "foi votado rapidamente, entre novembro de 2016 e março de 2017, eliminando as barreiras legais para a terceirização de qualquer atividade das empresas” (Marcelino e Galvão, 2020, p. 165).

A principal reação dos sindicatos ao ataque do empresariado com as propostas de reforma, então em tramitação no Congresso nacional, consistiu na greve geral de 28 de abril de 2017, que, organizada por praticamente todas as centrais sindicais atingiu mais de 150 cidades do país e contou com a adesão de 40 milhões de pessoas. A batalha contra a terceirização irrestrita, contudo, já estava perdida. Com a aprovação da reforma trabalhista, a terceirização em todas as atividades econômicas foi reforçada com a Lei 13.429/2017, que permite a terceirização ilimitada, sem qualquer regulamentação, em todas as atividades da empresa, Ao mesmo tempo, a lei prevê que a responsabilidade da empresa tomadora seja apenas subsidiária, caso a empresa de locação de mão de obra não cumpra com suas obrigações trabalhistas, o que significa que o traba- 
lhador só pode acessar a Justiça do Trabalho depois que se esgotem todas as tentativas de cobrança da terceirizada.

O impeachment representou, nesse sentido, não só a derrota do PT, que foi apeado do poder; significou, também, uma profunda derrota do movimento sindical frente ao avanço dos ideais do neoliberalismo que vinha propondo de maneira cada vez mais enfática a contenção dos custos do trabalho por meio das reformas e da extensão da terceirização, sem nem sequer considerar as empresas tomadoras como solidárias das responsabilidades das terceirizadas com relação a seus trabalhadores.

\section{CONSIDERAÇÕES FINAIS}

Além do abalo na democracia, o impeachment de 2016 representou um golpe contra os trabalhadores/as brasileiros, de magnitude inédita na história do país. Com a aprovação da terceirização irrestrita e da reforma trabalhista, que confirmou a extensão da terceirização a todas as atividades econômicas, em 2017, mais de 7 décadas de avanço da institucionalidade protetora do trabalho se desmoronaram. ${ }^{5}$ Nesse processo, o avanço da terceirização foi galopante, constituindo-se, numa das mais frequentes medidas de flexibilização negociadas pelos sindicatos depois da reforma (Véras de Oliveira; Galvão e Campos 2019). A capacidade ন্ de resistência sindical, contudo, já se via fori temente abalada desde a reforma, a partir da \% qual os sindicatos se viram ameaçados em sua própria existência e voltaram suas atenções e จึ estratégias à sobrevivência de suas estruturas ¿. administrativas e de pessoal (Véras de Oliveira; लే Galvão e Campos, 2019; Campos et al. 2021).

Apesar da busca de novas formas de ação, voltadas para a unificação das centrais, esse movimento ainda é incipiente e tem tido

5 No que concerne à terceirização, sua extensão a todas as atividades foi corroborada pelo STF que, em julgamento de 30/08/2018, concluiu, por maioria, "ser constitucional a terceirização em todas as etapas do processo produtivo" (Biavaschi, 2021, p. 435). que enfrentar uma série de dificuldades, entre as quais o fato de que as bases sindicais ainda não estão mobilizadas nesse sentido (Campos et al., 2021). Retomando a ideia do pêndulo, podemos dizer que, desde 2017, após um vigoroso processo de lutas, ele tombou bruscamente para o lado do patronato, promovendo a maior derrota do movimento sindical e da classe trabalhadora na história do país.

Além da precarização do trabalho, provocada pela terceirização e pela reforma trabalhista, o movimento sindical amarga a realidade de ter que enfrentar o enfraquecimento de suas instituições, pela própria expansão da terceirização, pela diminuição de suas fontes de financiamento e pelo esvaziamento das negociações coletivas promovidas pela reforma trabalhista (Leite, et al. 2021; Véras de Oliveira; Galvão e Campos, 2019). O retrocesso vivido pelo movimento sindical pode ser dimensionado tanto por sua pouca capacidade de reagir ao quadro atual de perdas de direitos dos trabalhadores, aprofundado nos últimos anos, com a pandemia, como sua fraca presença atual no debate público ${ }^{6}$.

Evidentemente, o pêndulo da história não para e é possível que numa nova conjuntura, o movimento sindical possa retomar sua capacidade de organização e mobilização e que a terceirização possa ser regulamentada de forma mais favorável aos trabalhadores. Isso, contudo, dependerá não só do próprio movimento sindical, mas de um processo de mobilização de toda a sociedade brasileira pela re-democratização do país, pelo respeito aos direitos do trabalho e a suas formas de organização.

Recebido para publicação em 08 de junho de 2021 Aceito em 16 de novembro de 2021

\footnotetext{
${ }^{6}$ Isso não significa que ele não esteja participando de momentos importantes das decisões nacionais, como foi o caso da pressão sobre o Congresso para a aprovação do auxílio emergencial de R\$ 600,00 em 2020, por conta da pandemia, assim como, em 2021, com o lançamento da Agenda Legislativa das Centrais Sindicais no Congresso Nacional (Prioridades para 2021. Vida, emprego e democracia), as quais são frutos do esforço de união das Centrais, acima apontado.
} 


\section{REFERÊNCIAS}

ALMEIDA, Paula; KALIL, Renan; FONSECA, Vanessa. A disputa política em torno da regulação do trabalho via plataforma digital e os entregadores motofretistas. In: KREIN, José Dari et al (Orgs). O trabalho pós reforma trabalhista (2017) vol. I. São Paulo: Cesit- Centro de Estudos Sindicais e de Economia do Trabalho, 2021.p. 474-511.

BIAVASCHI, Magda. A "reforma" trabalhista e as instituicões públicas do trabalho: impactos na judicialização dos conflitos. In: KREIN, José Dari. et al (Orgs). O trabalho pós reforma trabalhista (2017) v. 1, op. cit, 2021. p. 395-442

BIAVASCHI, Magda; DROPPA, Alisson. A dinâmica da regulamentação da terceirização no brasil: as súmulas do tribunal superior do trabalho, os projetos de lei e as decisões do supremo tribunal federal política \& trabalho, Revista de Ciências Sociais - Política \& Trabalho, [S. l.], v. 2, n. 41, 2015. p. 121-145.

BIAVASCHI, Magda; SANTOS, Anselmo. A terceirização no contexto da reconfiguração do capitalismo contemporâneo: A dinâmica da construção da Súmula 331 do TST. Revista do TST, 2014, p. 19-35.

BORGES, Angela; FRANCO, Tania. Mudanças de gestão: para além dos muros da fábrica. In: FRANCO, Tânia (Org.) Trabalho, riscos ambientais e meio ambiente: rumo ao desenvolvimento sustentável. Salvador: EDUFBA, 1997. p. 63-116.

BRESCIANI, Luis Paulo. Flexibilidade e reestruturação. O trabalho na encruzilhada. São Paulo em perspectiva, 11(1) 1997. p. 88-97.

CARDOSO, Adalberto. Trabalhar, Verbo Transitivo: Trajetórias Ocupacionais de Trabalhadores da Indústria Automobilística. Dados, vol. 41 n. 4 Rio de Janeiro 1998. p 1-32.

CARNEIRO, Ricardo. Texto para Discussão 289. Instituto de Economia, Unicamp. Navegando a contravento. (Uma reflexão sobre o experimento desenvolvimentista do Governo Dilma Rousseff). 2007, 40 ps. (Acessado em 24/05/2021). Disponível em: https://www.google.com. $\mathrm{br} / \mathrm{h}$ ? source $=\mathrm{hp} \& \mathrm{ei}=\mathrm{NI} 2 \mathrm{RW}$ sG1JoimwgSJwomoAg\&btnG $=$ Pesquisar\&q=Ricardo + Carneiro $\% 2 \mathrm{C}+2017 \&$ oq=ipva\& gs = psyab.1.0.35i39k1j0l3j0i67k1j0l2j0i131k1j0l2.1797. $2820.0 .7354 .5 .4 .0 .0 .0 .0 .114 .315 .1 j 2.3 .0 \ldots . . .01 \mathrm{c} .1 .64 . p s y-$ ab..2.3.315.0...0.6vMiczo8axA. Acesso em: 20.09.2021.

CASTRO, Nadya. A máquina e o equilibrista, São Paulo: Editora Paz e Terra, 1995

CASTRO, Nadya. et al. Trajetórias ocupacionais, desemprego e empregabilidade: há algo de novo na agenda dos estudos sociais do trabalho no Brasil? Rio de Janeiro: Contemporaneidade e educação. 1997, p 7-23.

CONCEIĈ̃A, Jefferson. Quando o apito da fábrica silencia. São Bernardo do Campo: ABCD Maior, 2008.

CONCEIĈÃO, Jefferson; LIMA, Cláudia. Empresários e trabalhadores diante da regulamentacão da terceirização: é possível um acordo mínimo? In: DAU, Denise et al. (Orgs.) Terceirização no Brasil: do discurso da inovação à precarização do trabalho. São Paulo: Annablume, CUT, 2009, p. 187-214.

CORIAT, Benjamin. Pensar al revés. Trabajo y organización en la empresa japonesa. Madri: Siglo Veinteuno de España Editores.1993.

COELHO, Elaine. O projeto de lei complementar $\mathrm{n}^{0}$ 30/2015 sobre a terceirização e as consequências para os trabalhadores brasileiros. In: Marilane Teixeira, Hélio Rodrigues e Elaine Coelho (Orgs). Precarização e terceirização: faces da mesma realidade. São Paulo: Sindicato dos Químicos, 2016
COSTA, Graça. A luta contra a terceirização sem limite. In: TEIXEIRA, Marilane et al. (Orgs). Precarizacão e terceirização: faces da mesma realidade. São Paulo: Sindicato dos Químicos, 2016, p. 213-227.

COUTINHO, Grijalbo. Terceirização: moendo e matando trabalhadores In: TEIXEIRA, Marilane et al. Precarização e terceirização: faces da mesma realidade. São Paulo: Sindicato dos Químicos, 2016, p. 187-212.

DAU, Denise. A expansão da terceirização no Brasil e a estratégia da CUT de enfrentamento à precarização do trabalho. In: DAU, Denise et al. (Orgs.). Terceirização no Brasil: do discurso da inovação à precarização do trabalho. São Paulo: Annablume, CUT, 2009, p.111-124.

DIEESE. Dossiê Terceirização e Desenvolvimento - Uma conta que não fecha. Secretaria. Nacional de Relações de Trabalho e Departamento Intersindical de Estatística e Estudos Socioeconômicos. - São Paulo: Central Única dos Trabalhadores, $2014.56 \mathrm{p}$.

DRUCK, Graça. Terceirização: (des)fordizando a fábrica - Um estudo do complexo petroquímico da Bahia. São Paulo: Boitempo, 1999.

DRUCK, Graça; FILGUEIRAS, Vitor. A epidemia da terceirização e a responsabilidade do STF. Rev. TST, Brasília, v. 80, n. 3, jul/set 2014, p. 106-125.

DUTRA, Renata. Call centers no Brasil: uma vitrine do mundo do trabalho após eventual aprovação do PLC $n^{\circ}$ 30/2015? In: TEIXEIRA, Marilane et. al. (Orgs), Precarização e terceirização: faces da mesma realidade. São Paulo: Sindicato dos Químicos, 2016, p. 69-90.

FETQUIM. Na luta para proteger e ampliar direitos. In: TEIXEIRA, Marilane et al. Precarização e terceirização: faces da mesma realidade. São Paulo: Sindicato dos Químicos, 2016, p. 13-14

FILGUEIRAS, Vitor. Terceirização e trabalho análogo ao escravo: estreita relação na ofensiva do capital. In: TEIXEIRA, Marilane et al (Orgs). Precarização e terceirização: faces da mesma realidade. São Paulo: Sindicato dos Químicos, 2016, p. 91-110.

FRANCO, Tania.; DRUCK, Graça. A degradação do trabalho e os riscos industriais no contexto da globalização, reestruturação produtiva e das políticas neoliberais. In: FRANCO, Tânia; DRUCK, Graça. Padrões de industrialização, riscos e meio ambiente. Ciência \& Saúde Coletiva, vol. 3, núm. 2, Associação Brasileira de Pós-Graduação em Saúde Coletiva Rio de Janeiro, Brasil, 1998, p. 61-72.

FREIRE da SILVA, Carlos, Trabalho informal e redes de subcontratação: dinâmicas urbanas da indústria de confecções em São Paulo. 2008. 147 p. Dissertação (Mestrado em Sociologia), Programa de Pós-Graduação em Sociologia da Universidade de São Paulo - USP.

KREIN, José Dari. Tendências recentes nas relações de emprego no Brasil - 1990/2005. 2007. 347 p. Tese (Doutorado em Economia) - Programa de Pós-Graduação em Economia do IE/UNICAMP.

LAPA, Thais; LEITE, Marcia. O trabalho no setor eletroeletrônico: o Brasil na cadeia global. In: SALAS, Carlos, et al. (Orgs.). Trabalho e regulação em perspectiva comparada. 1ed.São Carlos: Editora da Universidade Federal de São Carlos, 2017, v. 1, p. 311-330.

LEITE, Marcia. Trabalho e Sociedade em transformacão. Mudanças Produtivas e Atores Sociais. São Paulo: Editora Perseu Abramo, 2003

LEITE, Marcia, et al. Horizontes de enfrentamento das desigualdades de gênero no trabalho no Brasil. CLACSO 2021. Disponível em: https://www.clacso.org/becas/policybrief/. Acesso em: 20.09.2021.

LIMA, Jacob. "A terceirizacão e os trabalhadores: revisitando algumas questões". Cadernos de Psicologia 
Social do Trabalho, 2010, vol. 13, n.01, p. 17-26.

MARCELINO, Paula. Trabalhadores terceirizados e luta sindical. Curitiba: Appris, 2013, 308 p.

MARCELINO, Paula; GALVÃO, Andreia. O sindicalismo brasileiro frente à ofensiva neoliberal restauradora. Tempo Social, revista de sociologia da USP, v. 32, n. 1, 2020. p. 157-182.

MARTINS, Heloisa Helena; RAMALHO, José Ricardo. Terceirização - Diversidade e Negociação no Mundo do Trabalho. São Paulo: Hucitec, 1994.

NERI, Marcelo, et al. Mercado de trabalho nos anos 90: fatos estilizados e interpretações. IPEA, texto para discussão n ${ }^{\circ}$ 743. Rio de Janeiro, julho de 2000. 31 ps.

PIORE, Michael; SABEL, Charles. The second industrial divide. Possibilities for Prosperity, 1984.

POCHMANN, Marcio. A superterceirização dos contratos de trabalho. Campinas: SINDEEPRES, abril 2007. Disponível em: https://pndt.jusbrasil.com.br/noticias/2860161/marciopochmann-compara-terceirizacao-a-uma-quase-reformatrabalhista. Acesso em 20/05/2021.
RAMALHO, José Ricardo. Novas fronteiras de pesquisa na sociologia do trabalho, Política \& Sociedade, n. 13, outubro de 2008, p. 229-249.

SEGNINI, Liliana. Reestruturação nos Bancos no Brasil: Desemprego, subcontratação e intensificação do trabalho. Educação \& Sociedade, ano 20, no. 67, agosto 1999. p. 183209.

VÉRAS de OLIVEIRA, Roberto. Sindicalismo e terceirização no Brasil: pontos para reflexão. Caderno $C R H$, Salvador, v. 28, n. 75 p. 545-567, 2015.

VÉRAS de OLIVEIRA, Roberto; GALVÃO, Andréia; CAMPOS, Anderson. Reforma trabalhista: impactos imediatos sobre os sindicatos e primeiras reações. Cadernos do CEAS, Salvador/Recife, n. 248, p. 668-689, set./dez., 2019

VIANA, Marcio. A terceirização revisitada: algumas críticas e sugestões para um novo tratamento da matéria. Revista do TST, São Paulo, v. 78, n. 4, p. 198- 224, out./ dez. 2012 


\section{OUTSOURCING IN BRAZIL: the clash between unions and employers}

Marcia de Paula Leite

This article aims to discuss the reaction of Brazilian unions to the process of labor outsourcing, from when the process took on greater importance in the last decade of the last century, until its extension to all economic activities, in 2017. The text takes into account especially the action of trade union centrals in relation to business practices, while discussing the changes in legislation promoted since the 1990s. Upon recovering union activities, the analysis focuses on the vigorous clash between unions and businessmen in the period 2003-2016, in which the unions staged a fierce struggle against the business project of expanding outsourcing to all economic activities, and concludes that the intervention capacity of the union movement was one of the factors that led the ruling classes to promote the impeachment of 2016. The text is based on a discussion of the bibliography and on research results that I have been developing the last few decades.

KEY WORDS: Internal outsourcing. External outsourcing. Unrestricted outsourcing. Unionism. Union protagonism.

\section{L'EXTERNALISATION AU BRÉSIL: \\ le clash entre syndicats et patronat}

\author{
Marcia de Paula Leite
}

Cet article vise à discuter sur la réaction des syndicats brésiliens au processus d'externalisation de la main-d'œuvre, depuis le moment où le processus a pris une plus grande importance dans la dernière décennie du siècle dernier, jusqu'à son extension à toutes les activités économiques, en 2017. Le texte prend en compte en particulier l'action des centrales syndicales par rapport aux pratiques des entrepreneurs, tout en discutant des changements de législation promus depuis les années 1990. À la reprise des activités syndicales, l'analyse se concentre sur l'affrontement vigoureux entre les syndicats et les entrepreneurs dans la période 2003-2016, au cours de laquelle les syndicats ont mené une lutte acharnée contre le projet des entreprises d'étendre l'externalisation à toutes les activités économiques, et conclut que la capacité d'intervention du mouvement syndical a été l'un des facteurs qui ont conduit les classes dirigeantes à promouvoir la destitution de 2016. Le texte s'appuie sur une discussion sur la bibliographie et sur les résultats des recherches que j'ai développées les dernières décennies.

Mots CLÉs: Externalisation interne. Externalisation externe. Externalisation illimitée. Syndicalisme. Protagonisme syndical.

Marcia de Paula Leite - Doutora em Ciências Sociais pela USP. Professora Titular pela Unicamp. Professora Permanente do Programa de Pós Graduação em Educação do Departamento de Ciências Sociais e Educação. Universidade Estadual de Campinas, Unicamp. Coordenadora do Programa de Pós Graduação em Educação, Heloisa Helena Pimenta Rocha, desenvolvendo pesquisas na área de Sociologia do Trabalho. Publicações recentes: LEITE, M.; BIAVASCHI, M.; VELAZQUEZ, B.; LAPA, T. Horizontes do enfrentamento das desigualdades de gênero no trabalho no Brasil, CLACSO, 2021. https://www.clacso. org/becas/policy-brief/ ; LEITE, M. P. Les réformes récentes du code du travail au Brésil et en France: une analyse comparée 01/2020. BRÉSIL(S) - SCIENCES HUMAINES ET SOCIALES, v. 18, p. 1-20, 2020; LEITE, M. P. (Org); BIAVASCHI, M. B. (Org); SALAS, C. (Org); LIMA, J. C. (Org) O Trabalho em Crise: flexibilidade e precariedades. São Carlos, EdUFSCar, 2020, 275p. 
